\title{
Rancang Bangun Trainer Kontrol dan Monitoring Constant Current Regulator Augier Diam 4000 Berbasis Mikrokontroler sebagai Media Pembelajaran di Akademi Teknik dan Keselamatan Penerbangan Surabaya
}

\author{
Hartono \\ Dhoriyah Vataty Rizka Maulina \\ Program Studi Diploma III Teknik Listrik Bandar Udara \\ Akademi Teknik dan Keselamatan Penerbangan Surabaya \\ Jl Jemur Andayani I/73 Wonocolo Surabaya 60236 \\ Telp.(031)841087, Fax. (031)8490005
}

\begin{abstract}
ABSTRAK
Rancang Bangun Trainer Kontrol dan Monitoring Constant Current Regulator (CCR) adalah rancangan control antara mikrokontroller dengan touchscreen. Rancangan ini digunakan untuk menyempurnakan penggunaan trainer constant current regulator sebagai sarana pendukung media pembelajaran di Akademi Teknik dan Keselamatan (ATKP) Surabaya. Kontrol trainer CCR dioperasikan melalui touchscreen untuk mengatur step brightness lampu yang menggunakan komunikasi serial berupa ethernet shield yang dihubungkan oleh kabel UTP/LAN. Dan untuk monitoring juga dapat dipantau melalui data yang terdapat pada touchscreen besar arus konstan dan tegangan yang dapat berubah-ubah sesuai beban.
\end{abstract}

Kata Kunci: Constant Current Regulator (CCR), Mikrokontroller, Ethernet, Touchscreen

\section{ABSTRACTION}

Design of Trainer Control and Monitoring Constant Current Regulator (CCR) is the design of the microcontroller with touchscreen control. It is used to enhance the use of constant current regulators trainer as a means of supporting learning media at Civil Aviation and Safety Academy Surabaya. CCR trainer controls are operated via touchscreen to adjust the brightness step lights that use serial communications such as ethernet shield which is connected by UTP cable / LAN. The monitoring can also be monitored through the data contained in a large touchscreen constant current and voltage can vary according to the load.

Keywords: Constant Current Regulator (CCR), Microkontroller, Ethernet, Touchscreen

\section{Pendahuluan}

ATKP Surabaya merupakan lembaga pendidikan yang terdapat beberapa program studi di dalamnya, salah satunya yaitu program Studi Teknik Listrik Bandara yang memiliki laboratorium AFL (Airfield Lighting) yang disana ada beberapa alat untuk menunjang mata kuliah Sistem Penerangan Bandara, prototype Airfield Lighting dan Simulator Airfield Lighting. Pada program studi Teknik Listrik Bandara ini ada suatu alat yaitu Constant Current Regulator tipe AUGIER DIAM 4000, ini merupakan suatu alat pokok yang digunakan pada penyuplai power lampu Airfield Lighting (AFL). 
Peralatan praktik di laboratorium AFL tersebut sebenarnya sudah sangat lengkap, tetapi masih ada beberapa peralatan yang masih belum bisa maksimal dalam penggunaanya. Sebagai contoh 19iniature Airfield Lighting, lampu penerangan airside sudah dirangkai seri antar lampu dengan trafo seri yang sesuai dengan yang ada di lapangan. Akan tetapi untuk CCR yang telah terpasang sebagai catu daya utama bagi penerangan airside tersebut belum bisa untuk dianalisa tiap-tiap bagian peralatan yang terpasang pada CCR AUGIER DIAM 4000 yang terdapat di laboratorium AFL. Maka dari itu penulis ingin merancang sebuah 19iniature Constant Current Regulator AUGIER DIAM 4000 sebagai tambahan penunjang sarana pembelajaran di Akademi Teknik dan Keselamatan Penerbangan Surabaya.

Berikut ini merupakan rangkaian sistem secara keseluruhan CCR AUGIER DIAM 4000 :

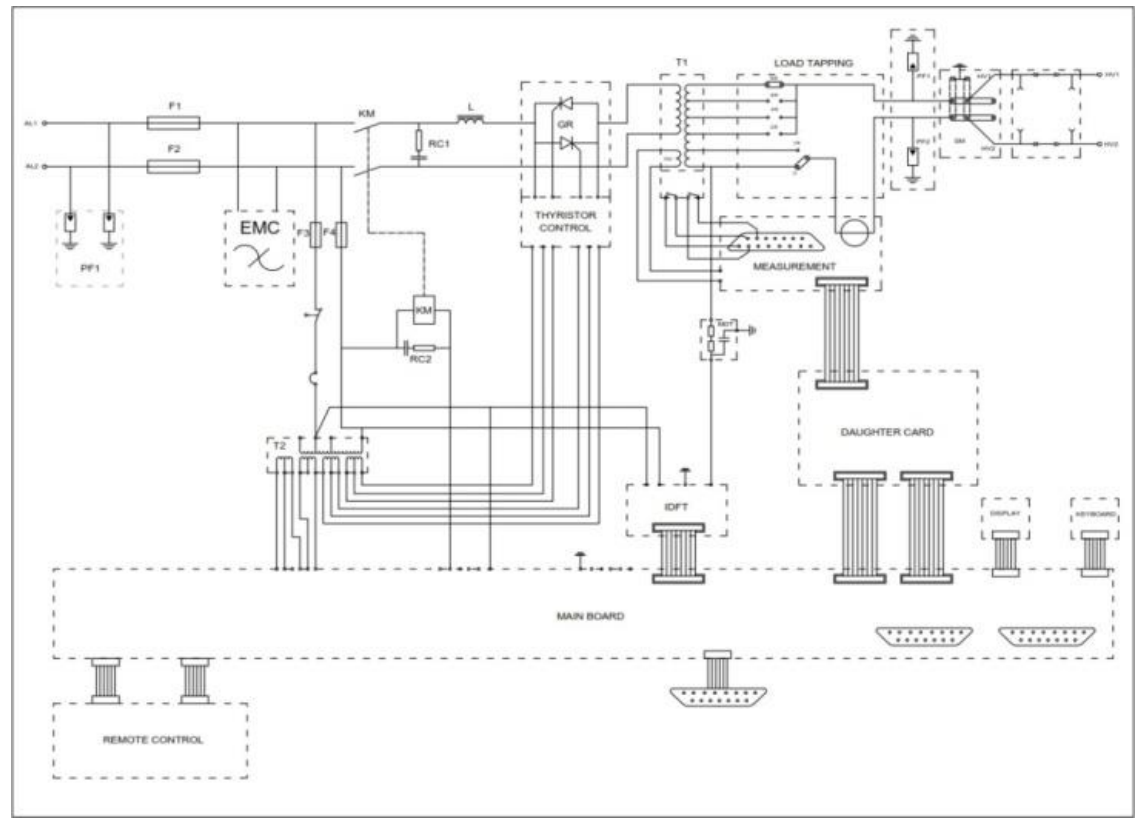

Gambar 1. Rangkaian Sistem CCR AUGIER DIAM 4000

Sumber : Hasil karya penulis

Berikut adalah blok diagram dari CCR AUGIER DIAM 4000 :

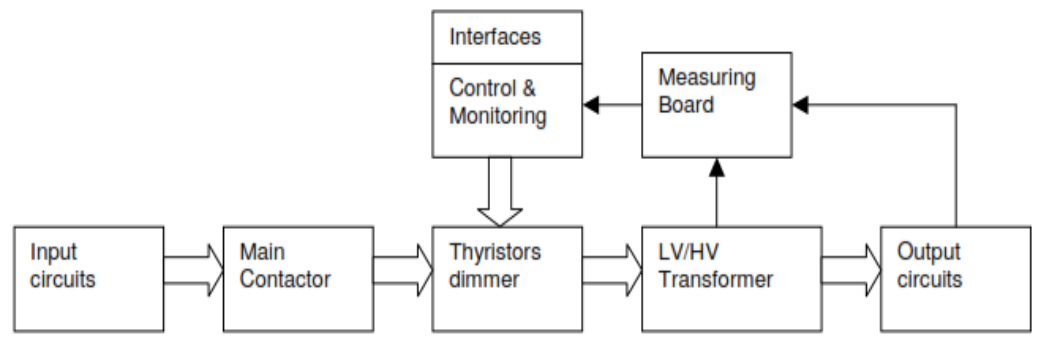

Gambar 2. Blok Diagram CCR AUGIER DIAM 4000

Sumber : Hasil karya penulis 


\section{Pembuatan Alat}

Rancangan alat yang akan dibuat adalah pengontrolan brightness lampu pada miniatur CCR type AUGIER DIAM 4000 menggunakan mikrokontroler arduino. Dalam rancangan ini mengembangkan sistem kontrol CCR type AUGIER DIAM 4000 yang masih menggunakan transistor akan dimodifikasi dengan mikrokontroler arduino untuk mewakili fungsi yang ada pada transistor. Sehingga dalam penerapannya juga dalam pengerjaannya lebih mudah dan sederhana.

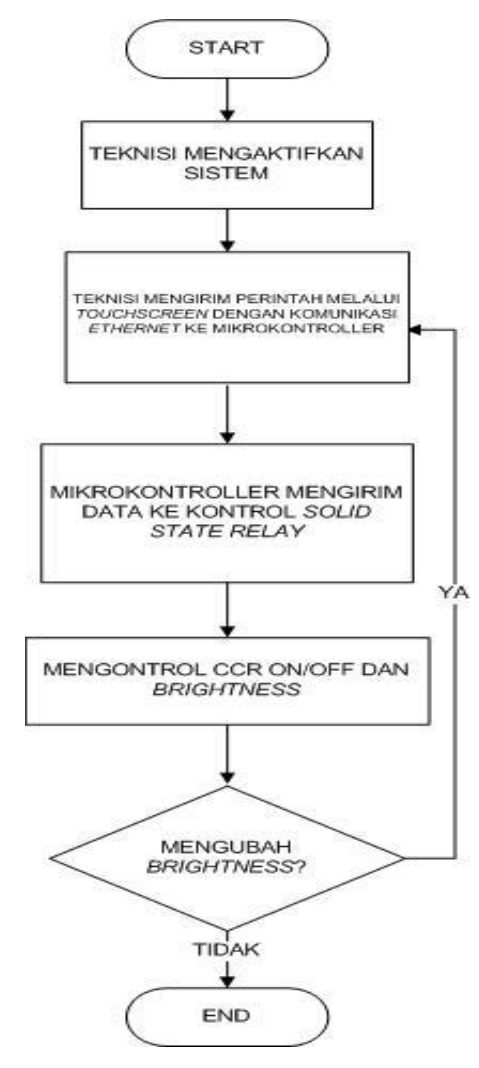

Gambar 3. Flowchart Rancangan Kontrol

Sumber : Hasil karya penulis

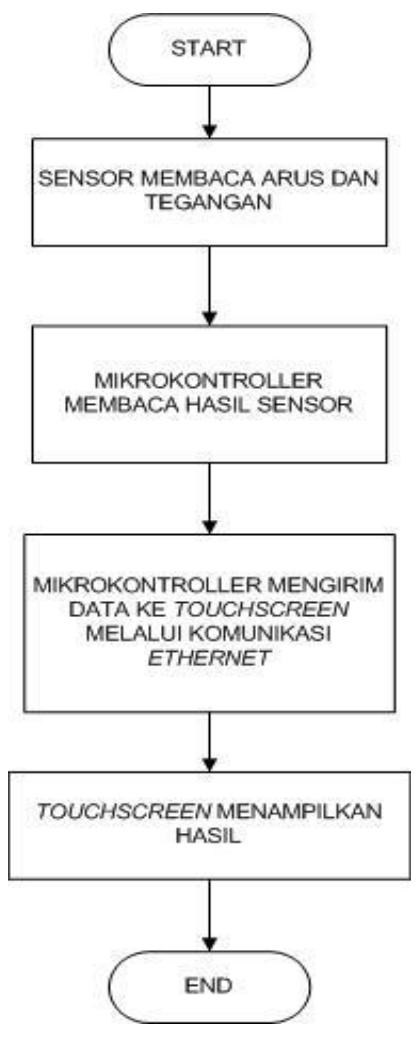

Gambar 4. Flow chart rancangan monitoring

Sumber : Hasil karya penulis

\section{Konsep Rancangan}

Untuk menyusun suatu miniatur/trainer yang hasilnya sesuai dengan yang diharapkan, maka diperlukan adanya suatu konsep rancangan untuk memberikan gambaran yang akan dirancang nantinya.

Untuk itu dibuat diagram blok untuk menggambarkan miniatur yang akan dirancang : 


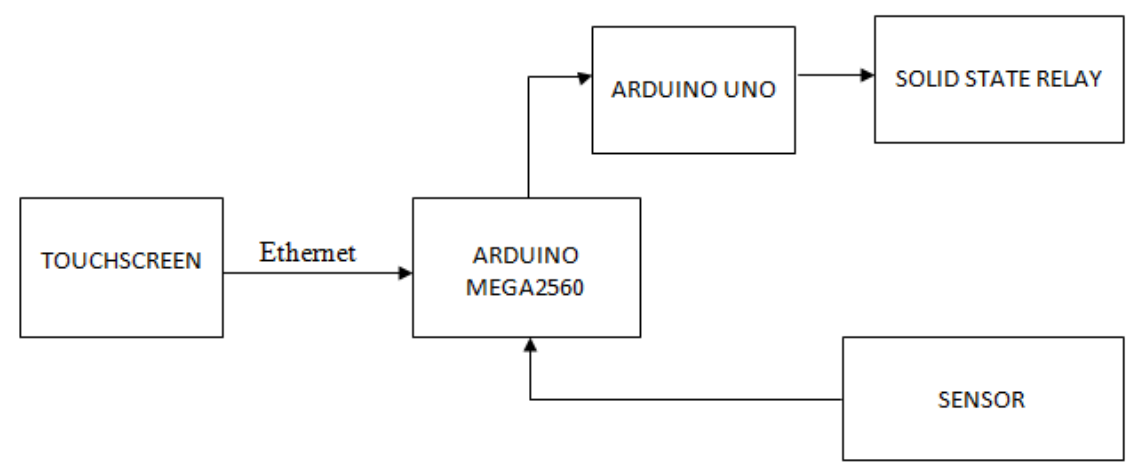

Gambar 5. Blok Diagram Rancangan

Sumber : Hasil karya penulis

Dari blok diagram diatas dijelaskan bahwa touchscreen yang akan mengirimkan perintah berupa step brightness yang dikirimkan pada Arduino melalui Ethernet berupa inisialisasi, agar dapat didefinisikan untuk diteruskan ke Arduino Uno dan memerintahkan Solid State Relay untuk mengatur arus konstan yang diinginkan. Begitupula sensor yang merupakan sensor arus dan tegangan terhubung langsung dengan Arduino Mega2560 yang akan mengirimkan besar arus dan tegangan agar dapat di monitoring pada layar touchscreen yang juga sudah di program pada Arduino Mega2560.

\section{Pengujian dan Analisa}

Pengujian ini dilakukan untuk mengetahui kinerja dari sistem dan untuk mengetahui apakah sistem yang telah dibuat sesuai dengan perencanaan atau belum. Pengujian terlebih dahulu dilakukan secara terpisah pada masing-masing unit rangkaian, kemudian dilanjutkan ke pengujian sistem yang telah terintegrasi secara keseluruhan.

\section{Pengujian Catu daya}

Catu daya yang digunakan adalah arus searah 12 VDC 5 A yang dihasilkan oleh Adaptor. Adaptor tersebut menyearahkan tegangan bolak - balik 220 VAC menjadi tegangan searah 12 VDC. Adaptor ini digunakan untuk memenuhi catu daya komponen - komponen yang ada yaitu sensor Arus, Sensor Tegangan, Sensor Kecepatan,mikrokontroller, Arduino Mega 25650, Ethernet Shield. Pada komponen - komponen tersebut membutuhkan tegangan 5 VDC dalam pengoperasiannya. 
Tabel 1 hasil pengukuran catu daya :

\begin{tabular}{|c|l|c|c|}
\hline No & \multicolumn{1}{|c|}{ Nama Komponen } & $\begin{array}{c}\text { Tegangan Yang } \\
\text { Diinginkan (Volt) }\end{array}$ & $\begin{array}{c}\text { Tegangan Yang } \\
\text { Terukur (Volt) }\end{array}$ \\
\hline 1 & Output Adaptor & 12 & 12 \\
\hline 2 & $\begin{array}{l}\text { Input Mikrokontroller } \\
\text { ATMega 16 }\end{array}$ & 5 & 5,1 \\
\hline 3 & Input Sensor Tegangan & 7 & 6,5 \\
\hline 4 & Input LCD 16 X 2 & 5 & 5,1 \\
\hline 5 & InputSpeed Drive & 8 & 7,9 \\
\hline 6 & $\begin{array}{l}\text { Input Port RS232 to USB } \\
\text { Converter }\end{array}$ & 5 & 5,1 \\
\hline
\end{tabular}

Untuk komponen-komponen seperti sensor Arus, Sensor Tegangan, Sensor Kecepatan, mikrokontroller ATMega 16, LCD 16 X 2, Speed drive, danPort RS232 to USB Converter sehingga dapat catu daya berada dalam kondisi baik.

\section{Pengujian Arduino Mega 2560}

Mikrokontroller yng digunakan merupakan Arduino Mega 2560, digunakan Arduino tipe ini karena memiliki jumlah I/O yang cukup untuk keperluan system dan memiliki internal Analog to Digital (ADC) dengan resolusi tinggi yaitu 10bit.

Pada mikrokontroller Arduino Mega 2560 terhubung pada Ethernet Shield, sensor arus, sensor tegangan.Mikrokontroller ini terdapat beberapa pin (masukan) dan port (keluaran). Pada pin yang mendapat data besar arus yang dikirim oleh sensor arus, dan data yang dikirim oleh sensor tegangan juga permintaan step brightness yang diminta oleh pengguna, lalu data tersebut diolah untuk ditampilkan pada layar touchscreen. Pada rangkaian ini penghubung antar Mikrokontroller dan layar touchscreen menggunakan media Ethernet mengguankan kabel UTP sebagai penghubungnya. Dengan demikian data yang dibaca oleh sensor arus dan tegangan dapat ditampilkan melalui layar touchscreen dan untuk memastikan arus yang diminta oleh pengguna sudah sesuai permintaan.

Dilihat dari hasil pengukuran yang sudah diujikan, Arduino Mega2560 dapat mengeluarkan output tegangan $\pm 5 \mathrm{VDC}$ dan Ethernet sebagai komunikasi dari hasil untuk kode sebagai inisialisasi yang akan dikirimkan ke touchscreen. 


\section{Pengujian Ethernet Shield}

Pengujian Ethernet shield dilakukan untuk memastikan data yang didapat dari Arduino Mega 2560 yang sudah dihubungkan melalui Ethernet untuk diolah dan dapat ditampilkan pada touchscreen menggunakan OPC client. OPC sendiri merupakan suatu standar teknologi yang memungkinkan kita mengambil suatu data dalam berbagai bentuk (serial, ethernet, RF, dll) tidak tergantung pada vendor manapun dan menampungnya dalam suatu server yang disebut OPC server.

Pada gambar di bawah dapat dilihat hasil pengujian Ethernet pada OPC untuk kode sebagai inisialisasi yang akan dikirimkan ke touchscreen menunjukkan bahwa Ethernet dalam keadaan baik.

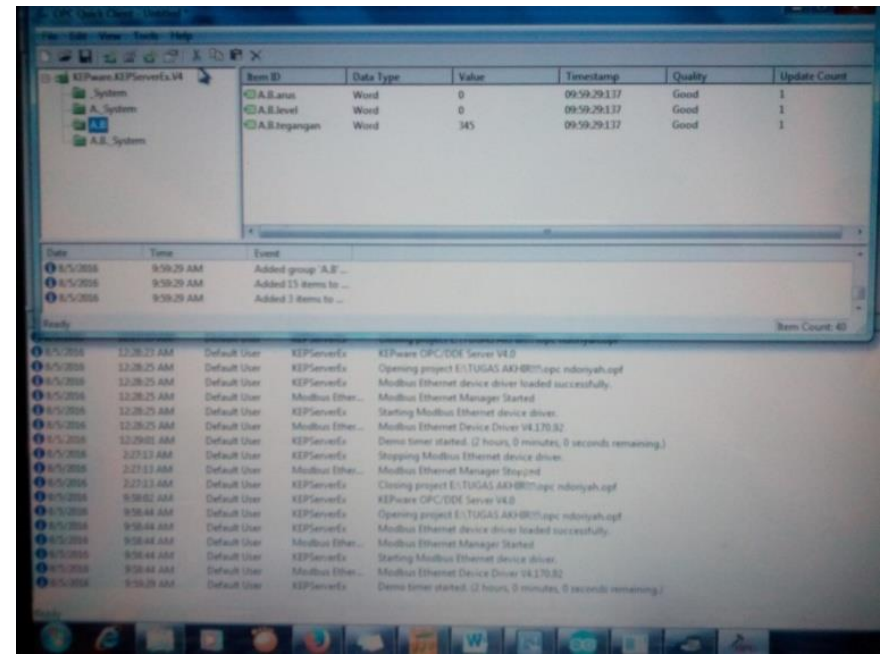

Gambar 6. Pengujian OPC

Sumber : Hasil karya penulis

\section{Pengujian Sensor Arus}

Pengujian sensor arus ini ditujukan untuk mengetahui arus yang telah diatur besarnya sesuai permintaan pengguna apakah sudah sesuai dengan yang diharapkan. Pengukuran Arus yang menggunakan sensor ACS712 yang kemudian akan ditampilkan melalui layar touchscreen.

Dari hasil pengujian didapatkan pembacaan sensor arus ACS712 sebagai berikut :

Tabel 2. Hasil Pengukuran Sensor Arus

\begin{tabular}{|c|c|c|}
\hline Brightness & $\begin{array}{c}\text { Arus Referensi } \\
\text { (A) }\end{array}$ & $\begin{array}{c}\text { Aruspada HMI } \\
\text { (A) }\end{array}$ \\
\hline 1 & 0.05 & 0.049 \\
\hline 2 & 0.07 & 0.072 \\
\hline 3 & 0.10 & 0.103 \\
\hline
\end{tabular}




\begin{tabular}{|c|c|c|}
\hline 4 & 0.12 & 0.121 \\
\hline 5 & 0.15 & 0.1502 \\
\hline
\end{tabular}

Arus referensi yaitu merupakan arus output yang sebenarnya digunakan skala perbandingan 3:3:1 dengan arus pada trainer.

\section{Pengujian Touchscreen}

Pada touchscreen sudah dapat terhubung dengan alat dan dapat beroperasi dengan semestinya, hanya saja pada tampilan terkadang terdapat peringatan kegagalan dalam menghubungkan alat karena untuk delay waktu penerimaan data pada alat dan touchscreen terlalu singkat \pm 1 detik.

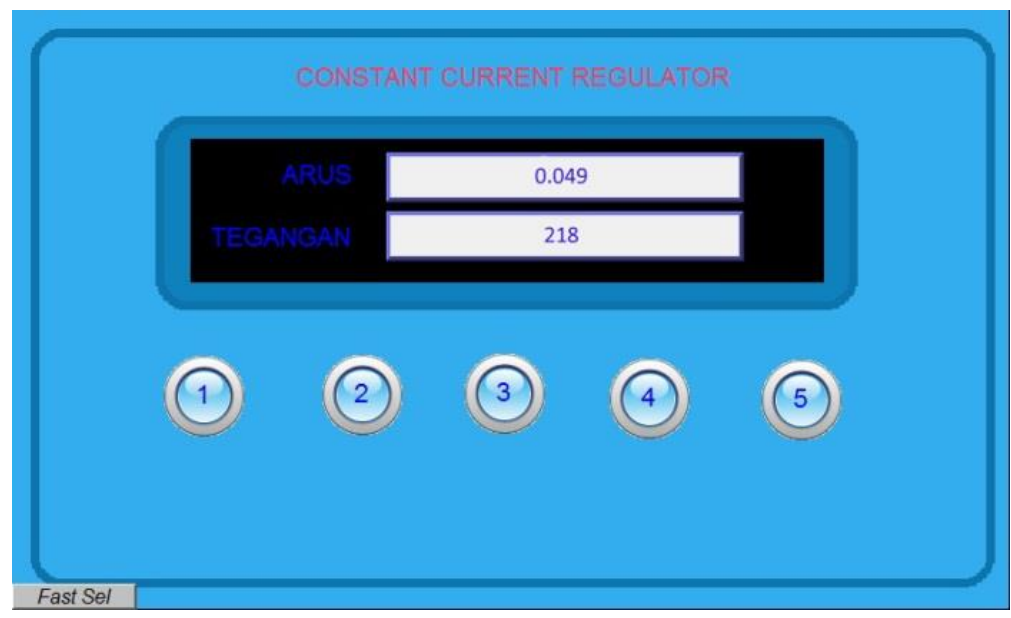

Gambar 7. Tampilan pada touchsreen

Sumber : Hasil Karya Penulis

Pada tampilan touchscreen terdapat Lima tombol untuk step brightness, diantaranya :

- Jika di tekan tombol angka " 1 " maka sistem akan meminta alat untuk memberi perintah arus yang mengalir step 1 sebesar 0.05 A.

- Jika di tekan tombol angka " 2 " maka sistem akan meminta alat untuk memberi perintah arus yang mengalir step 2 sebesar 0.07 A.

- Jika di tekan tombol angka "3" maka sistem akan meminta alat untuk memberi perintah arus yang mengalir step 3 sebesar 0.10 A.

- Jika di tekan tombol angka "4" maka sistem akan meminta alat untuk memberi perintah arus yang mengalir step 4 sebesar 0.13 A.

- Jika di tekan tombol angka " 5 " maka sistem akan meminta alat untuk memberi perintah arus yang mengalir step 5 sebesar $0.15 \mathrm{~A}$. 
Dari pengujian tiap komponen terbentuk suatu rancangan alat berupa control dan monitoring trainer CCR dengan hasil pengujian sebagai berikut :

Tabel 3. Hasil Pengukuran Sistem

\begin{tabular}{|c|c|c|c|c|}
\hline \multirow{2}{*}{ BRIGHTNESS } & \multicolumn{2}{|c|}{ ARUS (A) } & \multicolumn{2}{c|}{ TEGANGAN (V) } \\
\cline { 2 - 5 } & Referensi & Pada HMI & Input & Output HMI \\
\hline 1 & 0.05 & 0.049 & 50 & 218 \\
\hline 2 & 0.07 & 0.072 & 50 & 219 \\
\hline 3 & 0.10 & 0.103 & 50 & 219 \\
\hline 4 & 0.12 & 0.121 & 50 & 218 \\
\hline 5 & 0.15 & 0.1502 & 50 & 218 \\
\hline
\end{tabular}

Perbandingan antara arus referensi dengan arus pengukuran tidak berbanding jauh dengan toleransi $\pm 0.02 \mathrm{~A}$, sehingga trainer dianggap dapat bekerja secara baik. Untuk tegangan output HMI dengan tegangan 220 toleransi sebesar $\pm 5 \mathrm{~V}$.

\section{Kesimpulan}

Dari implementasi sistem serta hasil pengujian dan pengukuran terhadap sistem tersebut yang dibuat yaitu tentang Kontrol dan Monitoring Trainer Constant Current Regulator Augier DIAM 4000 dapat diambil kesimpulan sebagai berikut:

1. Pengendalian brightness lampu dapat dikendalikan melalui Touchscreen dengan media komunikasi Ethernet, yang dihubungkan dengan kabel UTP/LAN

2. Pengaturan step brightness lampu yang dikendalikan melalui touchscreen akan diproses oleh mikrokontroller yang terhubung dengan SSR yang mengatur arus konstan

3. Sensor arus dan tegangan digunakan sebagai monitoring arus dan tegangan yang mengalir ke beban untuk di monitoring sebagai interface pada touchscreen

\section{Saran}

Peralatan yang telah dibuat ini dapat disempurnakan lebih lanjut, seperti:

1. Untuk komunikasi Ethernet dapat diganti dengan kabel serial RS485 yang bias digunakan jarak jauh

2. Penggunaan touchscreen bisa digantikan fungsi kegunaannya menggunakan program tertentu melalui laptop atau komputer

3. Untuk monitoring arus bisa melalui Arduino Uno tanpa harus menggunakan sensor arus dan tegangan tambahan. 


\section{DAFTAR PUSTAKA}

Artanto D. 2012. Interaksi Arduino dan Lab View Jakarta (ID): PT Elex Media Komputindo. Astuti Budi.2013.Pengantar Teknik Elektro:Graha Ilmu

Syahwil Muhammad, 2013, "Panduan Mudah Simulasi dan Praktik: Mikrokontroler Arduino." Yogyakarta: Andi Publisher

Hydrocontrol. 2015 .Beginners guide to Arduino Ethernet Shield 2. Diambil dari : https://www.arduino.cc/en/Main/ArduinoEthernetShield(Juli 2016)

Brian. 2016 .DT-Sense Current Sensor with OpAmp.2016. diambil dari : http://innovativeelectronics.com/index.php?pg=ie_pdet\&idp=161 (Juli2016) 